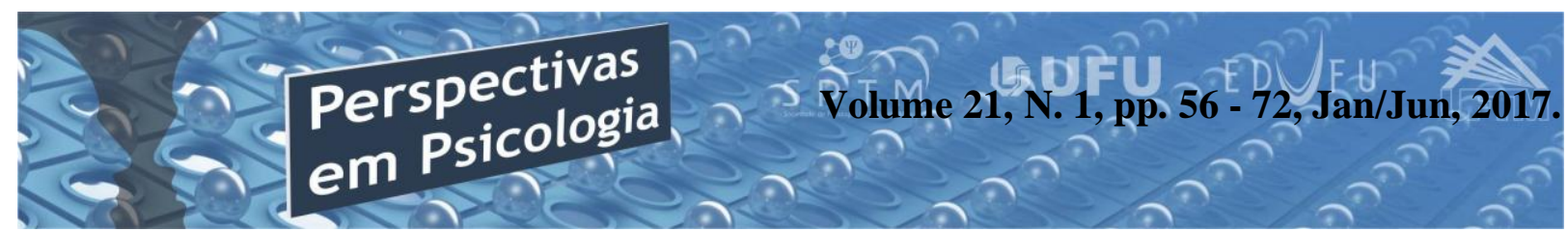

\title{
A IMPORTÂNCIA DO NARRAR E DO BRINCAR: UMA VISÃO PSICANALÍTICA
}

\author{
Fausto Pereira da Silva \\ Maria de Fátima Pessoa de Assis \\ (Universidade Federal de Goiás, Regional Jataí - UFG/RJ)
}

\begin{abstract}
Resumo
Vivemos em tempos acelerados, onde não há espaço para o descanso e para a espera, onde tudo precisa acontecer no aqui e agora. Este cenário produz efeitos danosos para as experiências infantis, dificultando a elaboração mental do vivido. $\mathrm{O}$ objetivo do presente estudo é resgatar a importância da narratividade e do brincar num mundo marcado pela utilização insana do tempo. Trata-se de uma pesquisa bibliográfica e teórica a partir de estudos clássicos e referentes aos últimos cinco anos. Verificou-se que o brincar e o narrar são importantes formas para a criança lidar com aspectos centrais do seu psiquismo, a partir dos quais pode apropriar-se do seu self e do seu meio, de acordo como seu desenvolvimento emocional e intelectual.
\end{abstract}

Palavras-chave: brincar; narrar; psicanálise; infância.

\section{Abstract \\ The Importance of Narration and Playing: A Psychoanalytic Vision}

We live in fast-paced times, where there is no room to rest and wait, where everything has to happen here and now. This scenario has damaging effects on children's experiences, making it difficult to elaborate their own mental experience. The purpose of the present study is to recover the importance of narration and playing in a world marked by the insane use of time. It is a bibliographical and theoretical research from classic studies and it refers to the last five years. It has been found that playing and narration are important ways for children to deal with central aspects of their psyche, from which they can appropriate of their self and environment, according to their emotional and intellectual development.

keywords: playing; narration; psychoanalysis; childhood.

Introdução
Na atualidade, o brincar espontâneo e o narrar perderam espaço para novas 
tecnologias como os jogos eletrônicos e tablets. Os pais também deixaram de ter tempo para seus filhos, pois todos estão apressados, guiados pela aceleração insana dos dias atuais. São impostas, cada vez mais, às crianças uma agenda lotada, como se fossem adultos e os pais preocupados com um futuro de sucesso profissional dos filhos, buscam meios para estimular precocemente o desenvolvimento intelectual destes, sem considerar os aspectos emocionais intrínsecos ao desenvolvimento infantil. No meio disso tudo, a criança se perde, é esquecida no que diz respeito à atenção, afeto, carinho e, principalmente na oferta de um tempo e um espaço onde possa brincar. Assim, o simples brincar, o fantasiar, o ouvir histórias, o "faz de conta", o tempo livre da criança, tanto em casa quanto na escola, deixam de ser valorizados por serem considerados "uma perda de tempo". Se cada segundo deve ser aproveitado e produtivo, não há tempo há perder. Assim, as consequências dessa temporalidade veloz são muito danosas e impedem o curso natural do desenvolvimento saudável do psiquismo infantil.

Nesse sentido, esta pesquisa bibliográfica e teórica aborda sobre o narrar e o brincar, assim como as suas implicações para o desenvolvimento psíquico infantil. Outro aspecto, não muito menos importante, é o de compreender a importância do resgate do contar histórias e de brincadeiras em meio aos apelos da sociedade de consumo e do desempenho. É sob a luz, principalmente, da psicanálise e de autores que se desdobraram no estudo do brincar e do narrar, como Winnicott, Safra e outros, que construímos nossos pressupostos e o desenvolvimento deste trabalho. Compreende-se que estas atividades são importantes formas para a criança lidar com aspectos centrais do seu psiquismo, de maneira que possa experimentar, testar, conhecer e apropriarse do seu mundo interno e do mundo externo. Sendo assim, a criança pode construir um entendimento gradativo dela própria e do seu meio, compatível como seu desenvolvimento emocional e intelectual.

\section{Contemporaneidade e temporalidade veloz}

$\mathrm{Na}$ atualidade vive-se em um tempo acelerado, um tempo ditado pelas máquinas industriais e pelos artefatos tecnológicos, onde não há espaço para o descanso e para a espera, contexto em que tudo precisa acontecer de imediato, no aqui e agora. Parar, significa produzir menos, perda de lucros, significa estar atrasado, desatento, é não estar antenado e nem conectado ao mundo virtual e às informações que chegam a todo o 


\section{A IMPORTÂNCIA DO NARRAR E DO BRINCAR: UMA VISÃO PSICANALÍTICA}

momento nos bombardeando de todas as maneiras. Ou seja, parar e descansar significam perder tempo.

No mundo contemporâneo, o tempo ganhou aceleração a partir da revolução industrial nos séculos XIX e XX e, mais ainda, depois do surgimento da informática no século XXI (Pripas, 2009). A temporalidade, aqui mencionada, envolve o tempo subjetivo (que se refere ao sentimento intrapsíquico da passagem do tempo). E sendo assim, cada pessoa pode sentir o tempo passar de uma determinada maneira. Expressões banais e corriqueiras como "correria da vida", "estou sem tempo", "o tempo é curto", "estou com pressa" são ditas e vividas como se fossem algo natural, de modo que o sentimento de urgência prevalece a todo instante.

Pripas (2009), em seu consultório médico percebeu que muitas das pessoas que o procuravam tinham como fator principal de sua doença o ritmo de vida. Pôde perceber, também, que o homem contemporâneo possui alguns aspectos básicos como o estresse, o tormento e a aflição. O motivo desses aspectos estarem presentes, segundo este autor, está no fato de o homem saber que é finito e, portanto, carregar continuamente consigo uma angústia, muitas vezes não nomeada, e, ao se deparar com o seu próprio silêncio e solidão que o assustam e o angustiam, ele busca uma maneira de lidar com issopor meio do prazer imediato e fácil.

O sentimento de vazio, a falta de sentido, as aflições e contradições aumentam a desordem interior do homem e o levam a procurar fora de si e nas promessas enganadoras do consumismo (os quais prometem a felicidade e longevidade) o sentido de existência. Assim, no mundo atual, a exterioridade se sobrepõe à interioridade, e se torna o eixo norteador das subjetividades. Entretanto, a transformação é dentro de si mesmo, no mundo subjetivo (Pripas, 2009). Para Winnicott (1975) e Safra (2011) tal transformação se dá no espaço potencial, aspecto sobre o qual abordaremos adiante.

Mas o que vem a ser o tempo tão enfatizado aqui? De acordo com Pripas (2009), o tempo é uma dimensão dentro da qual o homem nasce imerso e ele pode ser visto de maneiras diversas, seja na agricultura, na natureza ou nos calendários. Outra forma de pensar o tempo diz respeito ao tempo psíquico e existencial, que não se pode medir, é subjetivo e muito significativo em todas as nossas experiências.

Segundo Oliveira (2009), todos os seres humanos sentem a passagem do tempo psicológico desde o nascimento até a morte e, uma de suas peculiaridades é o fato de ele sempre fluir em uma única direção, ou seja, do passado para o futuro, 
de modo a permitir a sensação de continuidade. Assim, de acordo com esse mesmo autor, "o futuro sempre se configura com inúmeras possibilidades. $\mathrm{O}$ passado, ao contrário, é único e não pode ser alterado" (p. 19). Entre eles, existe o presente que se altera a cada instante. A percepção que se tem é que o tempo flui em um único sentido de uma maneira contínua e sem fim.

Quando se é criança a vida passa devagar, mas conforme ela vai crescendo, o seu ritmo de lentidão vai sendo substituído por uma temporalidade mais acelerada e compatível com a aceleração do mundo atual (Oliveira, 2009). $\mathrm{Na}$ sociedade contemporânea, "os valores mais altos são cunhados no sucesso, na competição, vitória, eficiência, produção e lucratividade" (Pripas, 2009, p. 33). Tudo gira em torno da aceleração, inclusive as atividades impostas pelos pais às crianças, como o estudo de novas línguas, esportes, informática, alfabetização, etc., aspectos do cotidiano que substituem muitas vezes a atividade mais importante na infância, que é o brincar, cujo significado pode perder a importância nesse contexto.

Este cenário produz efeitos danosos para as experiências do brincar e do narrar, quando os pais não têm mais tempo para se envolverem em brincadeiras e contação de histórias para as crianças. Os filhos são negligenciados, mesmo que de maneira não consciente e não deliberada, e os pais, na tentativa de justificar o seu distanciamento e falta de tempo, apenas dizem: "não tenho tempo", "estou com pressa".

Sendo assim, são as crianças as que mais sofrem com os efeitos da pressa produzida pelo mundo atual e são elas, talvez, as principais vítimas da orgia da aceleração (Honoré, 2005). Esta última é produzida pela urgência de que tudo tem que acontecer no aqui e agora, modo de lidar com o tempo que caminha na contramão do processo de constituição da vida psíquica e do desenvolvimento das crianças. Com efeito, as crianças estão a todo o momento sendo bombardeadas com imagens e abarrotadas de tarefas que são impostas no seu dia a dia, o que dificulta a elaboração mental de tudo o que vivenciam, ou seja, lhes são tiradas o direito à reflexão e à internalização de tudo o que experimentam. A elas são negadas o tempo da alma, o tempo da infância, da narratividade e do brincar tão importantes para a saúde psíquica humana. A construção do externo passa à frente da construção do que é interno. O ruído do cotidiano bloqueia a interiorização e, como diz Maria Bernadete no livro Cronos Ensandecido: "barulho e aceleração não combinam com a reflexão. A interiorização requer tempo e silêncio" (Pripas, 2009, p. 69). 


\section{A IMPORTÂNCIA DO NARRAR E DO BRINCAR: UMA VISÃO PSICANALÍTICA}

Da mesma maneira que falta tempo, falta espaço. Cada vez mais, as crianças encontram-se reclusas dentro de casas e apartamentos afastando-se dos espaços da rua, onde, antigamente, era palco de interação, de convivência e de trocas entre as crianças. Para Meira (2012), os espaços segregados, condomínios e prédios gradeados, assim como o afastamento das populações de classe baixa para a periferia da cidade, são fatores que ilustram a lógica capitalista. Não há espaço para o brincar e os sintomas psíquicos, segundo esta autora, são o isolamento, a depressão, a hiperatividade e a violência.

Tem sido preocupação crescente entre estudiosos da psicanálise (Winnicott D. W., 1975; Safra, 2006) as consequências nocivas para as crianças da falta de um tempo e de um espaço para as atividades lúdicas. É difícil, hoje em dia, encontrar crianças que se envolvam em atividades de montar casinhas, barracas, de propor lutas entre o bem e o mal, inventar histórias; tais atividades envolvem não apenas uma disposição de tempo e um brincar, mas um narrar sempre cheio de criatividade, sonhos e fantasias e de construção de laços afetivos. Elas estão cada vez mais conectadas aos seus aparelhos eletrônicos deixando de lado as brincadeiras coletivas, perdendo o tempo da conversa e da narrativa de histórias, recursos de linguagem que permitem nomear e fornecer sentido ao que é vivido (Corso \& Corso, 2006). A pressa pressupõe superficialidade, o tempo, profundidade.

Tendo em vista o que foi posto, o propósito do presente estudo não é o de abordar, de forma exaustiva, as consequências para o aparelho psíquico desse tempo acelerado no qual todos os homens estão inseridos, o que não cabe nos limites desta pesquisa, mas sim tentar trazer à tona a importância da narratividade e do brincar num mundo marcado pela utilização insana do tempo. Com efeito, parar, sentar e esperar, expressões compatíveis com o tempo da alma e com o tempo da criança (Pripas, 2009) não são permitidas, são negadas e negligenciadas. A construção psíquica requer tempo.

\section{O brincar: teoria e implicações}

Winnicott (1975) estudou a importância que tem o brincar para o desenvolvimento humano, destacando que é através do brincar que a criança pode assumir um viver criativo e saudável. O brincar remete ao início da vida, ainda quando o bebê acredita ser um só com a mãe, que fica atenta e busca satisfazer todas as necessidades deste. Mas, com o passar do tempo, ela vai deixando de atendê-lo prontamente, o que o faz aprender, aos poucos, a lidar com o 
fracasso dela. Esse processo de frustração feito pela mãe é importante para o bebê, pois é através dele que os objetos se tornarão reais e concretos. Assim, para que a mãe desempenhe esse papel com relativo sucesso é necessário que seja uma mãe suficientemente boa.

Para Winnicott, uma mãe suficientemente boa é aquela que atende pronta e completamente as necessidades do bebê de modo a lhe proporcionar a ilusão de que o objeto que o satisfaz, no caso o seio materno, é de sua própria criação, o que permite uma relação de confiança com a mãe. Nesse momento, a criança tem a experiência de controle mágico, ou seja, "experiência daquilo que é chamado de 'onipotência' na descrição de processos intrapsíquicos" (Winnicott D. W., 1975, p. 79).

A partir do estabelecimento do estado de confiança com a mãe, o bebê começa a desfrutar de sua onipotência, acreditando ter o controle dos objetos reais. É nesse estado de confiança que a mãe suficientemente boa cria o playground intermediário, onde a ideia de magia se origina. Tal experiência psíquica alivia a tensão suscitada pela articulação entre a realidade interna e externa. É importante salientar que esse playground é um espaço potencial entre a mãe e o bebê, espaço que une ambos e só é possível se o relacionamento estabelecido entre mãe e bebê for de confiança (Lins, 2006).

Dessa maneira, o brincar implica confiança e é pertencente ao espaço potencial existente entre o bebê e a mãe. $\mathrm{O}$ brincar não está dentro nem fora, mas na área intermediária da experiência, e é nesse espaço que a criança usufrui sua liberdade de criação. Winnicott (1975), diz que é no brincar, e somente no brincar, que a criança pode ser criativa e utilizar sua personalidade integral, e é somente sendo criativa que ela descobre o seu eu (self). A criatividade é característica da vida e do viver total, é uma proposição universal que se relaciona ao estar vivo.

Segundo Winnicott (1975), a criatividade é como um colorido de toda a atitude com relação à realidade externa e não apenas uma criação bem sucedida ou aclamada. Refere-se à abordagem do indivíduo à realidade externa, sendo que é por meio da criatividade que a pessoa se torna ativa e toma parte na vida da comunidade. É através da apercepção criativa que a criança sente que a vida é digna de ser vivida. Viver criativamente constitui um estado saudável.

A brincadeira, assim, é universal e própria da saúde. O brincar facilita o crescimento e, consequentemente, a saúde, assim como conduz aos relacionamentos grupais (Winnicott D. W., 1975). Para este autor, há uma evolução direta dos 


\section{A IMPORTÂNCIA DO NARRAR E DO BRINCAR: UMA VISÃO PSICANALÍTICA}

fenômenos transicionais e objetos transicionais para o brincar, do brincar para o brincar compartilhado, e deste para as experiências culturais.

Para compreender melhor sobre o uso de objetos, ditos transicionais, no espaço potencial, Winnicott trata da diferença entre a relação de objeto e o uso do objeto. Na relação de objeto, o sujeito permite que sejam feitas alterações no seu eu (self). O objeto tornou-se significativo, ou seja, mecanismos de projeção e identificação estiveram operando e o sujeito está esvaziado ao ponto de que algo que é seu possa ser encontrado no objeto. Aqui, como exemplo, temos a relação entre o bebê e a mãe/seio, onde aquele acredita que o seio nutridor é de sua criação e está fundido à ele, ou seja, acredita que a mãe seja uma extensão dele mesmo.

Já no uso de um objeto, é este que tem que ser usado e deve fazer parte da realidade compartilhada, e não um feixe de projeções (Winnicott D. W., 1975). Assim, ao examinar o uso do objeto deve-se levar em consideração a natureza deste, não como projeção, mas como coisa em si.

A mãe suficientemente boa pode fazer o bebê passar do relacionamento ao uso: "à medida que a frustração ocorre, quando a mãe não mais satisfaz o bebê, no instante mesmo em que este alucina o seio nutridor, e estando o ego mais organizado, o bebê qualifica a mãe como não-eu, separada dele" (Souza \& Assis, 2014). Aqui, o bebê já começa a fazer uso dos objetos não-eu, os chamados objetos transicionais, como o punho, os dedos, ponta do cobertor ou algum outro brinquedo, como se estivesse sugando o peito da mãe que outrora o nutria.

Portanto, fazendo uma retomada, primeiro, há a relação de objeto, depois, o uso deste. Entre esses dois, existe a colocação, pelo sujeito, do objeto fora da área de seu controle onipotente, isto é, a percepção do objeto como fenômeno externo, não como entidade projetiva. Essa mudança significa que o sujeito destrói o objeto, pois se tornou externo a ele. Numa sequência de desenvolvimento, depois de o sujeito se relacionar com o objeto, temos o sujeito que destrói esse objeto, e em seguida, a sobrevivência deste. A partir disso, o sujeito pode agregar valor a esse objeto que se torna também seu objeto de amor. O sujeito pode usar o objeto que sobreviveu, pois este, agora, possui autonomia e vida própria.

O postulado central de Winnicott nos mostra que enquanto o sujeito não destrói o objeto subjetivo (material de projeção e com o qual mantém relação), não consegue aceitar a realidade compartilhada.

Com efeito, o primeiro passo para a aceitação da realidade, requer a experiência coma primeira possessão não- 
eu, ou seja, é o objeto transicional que possibilita, por meio da capacidade criativa da criança, a construção de um mundo com o outro, onde o self pode existir como si mesmo. Assim, na constituição do self ou de sua evolução é necessário contemplar o próprio ato de criar, em que o tempo, o espaço, o gesto, o objeto, os símbolos são fundamentais em si mesmos (Safra, 2005).

De acordo com Winnicott (1975), é através da criatividade que o indivíduo descobre o seu self e sente que a vida vale a pena ser vivida. É descobrindo seu self que o indivíduo pode ser criativo, atuando sobre o meio em que vive. Ao contrário, se o indivíduo não puder ser criativo, ele se torna submisso à realidade, vendo o mundo apenas como um local ao qual deva se adaptar e se sujeitar. A saúde psicológica e criativa entra em declínio e o falso self emerge bloqueando o potencial de criatividade do indivíduo.

De acordo com Safra (2005) o mundo atual apresenta situações e problemas que levam o ser humano a ficar adoecido em sua possibilidade de ser. O ser humano vive fragmentado, descentrado de si mesmo, impossibilitado de encontrar, na cultura, os elementos e o amparo necessários para conseguir a superação de suas dificuldades psíquicas, queixando-se, cada vez mais, de vivência de futilidade, de falta de sentido na vida, de vazio existencial e de morte em vida.
Conforme já foi enunciado, o mundo atual é regido pelo capitalismo, tendo valor apenas aquilo que gera produtos a serem consumidos, deixando de lado a arte, o brincar, a narratividade, a religião, dentre outros. O brincar, visto como algo que nada produz, é considerado sem valor e categorizado como algo “infantil”, portanto, sem importância.

O brincar está na contramão da lógica capitalista, pois é uma atividade complexa, que envolve a criação de situações que exigem tempo e espaço para serem organizadas. Segundo Souza e Assis (2014), o brincar formula mundos, reconstrói a realidade, recria as vivências atribuindo a elas novas possibilidades diferentes daquelas que já tinham sido impostas. É no brincar que o indivíduo experimenta diversas maneiras de ser e é no brincar que se pode projetar o futuro, elaborar sentidos e transitar entre mundos e tempos. Nele, aparecem os anseios da criança, seus desejos e vontades que estimulam a esperança no futuro.

Segundo Morabito, Sei e Arruda (2012), hábitos, regras, aprendizados, capacidade de resolver problemas externos e conflitos externos, assim como a conquista de sentidos para a vida entram na vida da crianca, primeiramente, pela e como brincadeira. Observa-se que é pela brincadeira que a experiência social da 


\section{A IMPORTÂNCIA DO NARRAR E DO BRINCAR: UMA VISÃO PSICANALÍTICA}

crianca é atualizada, permitindo que ela transite entre dos diversos papeis sociais.

$\mathrm{Na}$ brincadeira a criança não apenas usa o brinquedo como símbolo de algo, mas também joga com os símbolos, isso quer dizer que, os brinquedos vão adquirindo vários significados a partir dos quais a criança se coloca em movimento, descobrindo, assim, outros sentidos de realidade e de vida (Souza \& Assis, 2014). A capacidade de usar símbolos, segundo Safra (2005), mostra a habilidade da criança de veicular uma experiência, uma vivência, dando ao símbolo um uso pessoal, cheio de criatividade. Quando não existe mais jogo ou brincadeira, o adoecimento se faz presente e a constituição do self não é estabelecida.

\section{O narrar}

O narrar, segundo Safra (2006; 2011), refere-se à possibilidade de se contar uma experiência. De acordo com esse autor, no cerne de todo narrar existe uma experiência, uma vez que, ao contar uma história ou situação, busca-se compartilhar tal experiência, tornando-a presente. Assim, o narrar é compartilhar uma experiência de vida, é presentificar sabedoria, ou seja, é ofertar um saber tácito sobre o viver humano, uma vez que, quem narra, já passou por inúmeras experiências e que, assim, incorpora um saber a respeito da existência humana (2006; 2011). Esse saber, apresentado pelo narrar, é ao mesmo tempo pessoal e transgeracional.

Entretanto, para que se possa narrar é preciso ser atravessado pela experiência e, na atualidade, as pessoas estão encontrando dificuldades em vivenciar a experiência narrativa. Para Safra (2006), essas pessoas vivem uma agonia sem contornos e sem referenciais: perderam o gesto, a possibilidade de ter voz e movimento em direção a um horizonte existencial. Assim, existe, hoje, a necessidade de recuperar a capacidade do ser humano de narrar. As crianças, ao mesmo tempo, que são auxiliadas pelas histórias que ouvem,adquirem a capacidade de contar um conto e compartilhar, assim, essa experiência com outras pessoas, possibilita-lhes o "refundamento da tradição que celebra o humano" (Safra, 2011, p. 8).

A criança tem uma tendência espontânea ao desenvolvimento, mas ao longo dele ela pode ter dificuldades de elaborar psiquicamente seus conflitos, acarretando a paralisação de seu crescimento e a formação de sintomas. Com o narrar, a possibilidade de facilitação de elaboração de conflitos vividos pela criança é aumentada, permitindo, assim, “à criança um desenvolvimento gradativo para um movimento criativo infantil" (Zatti \& Kern, 2014, p. 11). 
Safra (2011) buscou maneiras de auxiliar a criança na elaboração desses conflitos e foi nas histórias infantis que ele encontrou um modo de comunicação adequado ao momento do processo maturacional no qual a criança se encontra. Os contos mostram à criança questões humanas que ela vivencia, mas que não tem condições de verbalizar.

Segundo Ferro (1995), os contos permitem que a criança viva em outro lugar e em outro tempo, seus medos mais inconfessáveis e indizíveis, pelo fato desses medos estarem relacionados às pessoas que mais preza, como o pai e a mãe, assim como por representarem seus desejos e aspectos reais. Assim, os contos dão contorno aos desejos, permitindo que a criança vivencie-os sem culpa (Pereira \& Lemos, 2013).

Bettelheim (2002), fez um trabalho pioneiro no qual sistematizou a importância dos contos na vida psíquica da criança, onde defende que para que uma história contribua para o desenvolvimento saudável e faça sentido na vida da criança, é preciso que se fique atento ao estágio de desenvolvimento no qual ela se encontra e, também, àquilo que é mais significativo para ela naquele momento. Se não for significativo e não fizer sentido, não haverá interesse em ler ou ouvir uma história, nem mesmo transformações poderão ocorrer. Para este autor, a história precisa prender a atenção da criança e despertar sua curiosidade, ativando, então, sua imaginação que, por sua vez, possibilitará o desenvolvimento de seu intelecto e o clareamento de suas emoções, o que a faz aprender a lidar com suas ansiedades, aspirações e dificuldades que são inerentes ao existir humano. A criança carece muito que lhe seja ofertada ideias ou sugestões, em forma simbólica, sobre como ela pode lidar com suas questões e atingir a maturidade.

Bettelheim (2002) afirma que as histórias transmitem mensagens muito importantes à mente consciente, préconsciente e inconsciente da criança, em qualquer nível que esteja funcionando no momento. Elas falam ao ego em crescimento e encorajam seu desenvolvimento ao tratar de problemas humanos universais, particularmente daqueles que preocupam o pensamento da criança. Ao mesmo tempo, aliviam pressões e desejos pré-conscientes e inconscientes.

Para Safra (2011), as histórias não só possibilitam um modo de encontrar expressão para desejos inconscientes, mas fundamentalmente um modo de permitir à criança colocar seus conflitos subordinados à sua criatividade, ou seja, sob o domínio do eu.

Gutfreind (2010), em seus estudos e experiências, afirma que a criança encontra 


\section{A IMPORTÂNCIA DO NARRAR E DO BRINCAR: UMA VISÃO PSICANALÍTICA}

na literatura infantil um dispositivo para dominar a angústia e o medo. Assim, essa forma de expressão e domínio é imprescindível para o desenvolvimento cognitivo e ao enriquecimento da apercepção criativa - capacidade da pessoa de apreender a realidade segundo suas características pessoais - possibilitando à criança estar pessoalmente presente, sem estar submetida ao mundo externo nem tampouco interpretá-lo de forma delirante, mas sim por meio de uma compreensão pessoal do mundo que a rodeia (Safra, 2011).

As histórias têm sido usadas pela humanidade, ao longo dos tempos, com diversos objetivos, como os medicinais, educativos, religiosos, filosóficos, dentre outros. Com efeito, ao longo do tempo, elas serviram e servem como um instrumento de compartilhamento de experiências, de transmissão de notícias, conselhos, advertências, enfim, de experiências de vida. Em todos os povos podem ser encontradas histórias e mitos por meio dos quais os seus membros buscam a elaboração de angústias comuns e a transmissão de sua maneira subjetiva de ver e entender o mundo (Costa, Cadore, Lewis, \& Perrone, 2013; Lemos \& Silva, 2012; Granato, Corbett, \& AielloVaisberg, 2011). Nesse sentido, os contos fazem parte do inconsciente coletivo, sendo considerados como uma produção coletiva que é transmitida de geração para geração. São nas histórias ou nos contos que habitam os conflitos e conteúdos que são comuns a todos os seres humanos (Port, Henkin, Feijó, \& Brum, 2014).

Os contos possuem grande complexidade, segundo Safra (2006), já que abordam não só questões fundamentais da existência humana, mas as colocam de maneira articulada numa temporalidade de início, meio e fim. Nessas narrativas, a temporalidade humana está contemplada, pois o ser humano, desde cedo, inicia, vive e finaliza diferentes experiências ao longo da vida que, também, possui um início, meio e fim. Quando alguém ouve uma história já se pode pressentir que ela terá um fim, pois teve um começo e isso guarda intima relação com o ciclo de vida humano. Segundo Safra "o tempo da narrativa assemelha-se ao tempo do cozinhar, ao tempo do tecer, o que torna a narrativa um gênero literário artesanal" (Safra, 2006, p. 20).

Ainda que Winnicott não tenha trabalhado diretamente com o conto, interessou-se muito pela capacidade da criança de criar, imaginar, inventar e produzir um objeto, referindo-se a este como sendo reconhecido pela criança como um objeto não-eu, criado num espaço intermediário situado no limite entre o exterior e o interior, como demonstramos anteriormente. Este espaço 
potencial, seria, para Winnicott, a terceira área da vida de um ser humano, onde ele possa experimentar e vivenciar as diversas situações da vida.

É no espaço potencial que a criança consegue lidar de maneira satisfatória e criativa com a realidade objetiva, tendo um contato mais rico e saudável com o mundo externo (Winnicott D. W., 1975; Safra, 2011). Sendo assim, o lugar do conto é o espaço da criatividade, espaço potencial.

Assim, as histórias infantis, de acordo com Gutfreind (2010), podem constituir o objeto transicional, no qual a criança vai investir, apegando-se a ele, elaborando, assim, um universo imaginário que servirá de intermediário entre a criança e o ambiente externo.

Quando a mãe não consegue se adaptar de maneira satisfatória às necessidades do bebê, este, para sobreviver, necessita se submeter ao meio em que vive, o que leva a reagir frente ao mundo externo, perdendo a possibilidade de posicionar-se criativamente à realidade e sentir-se realmente vivo. Ao contrário, quando a mãe se adapta criativamente às necessidades do bebê, este tem a oportunidade de experimentar a continuidade de si ao longo do tempo. Deste modo, ao invés de reagir, o bebê faz um movimento espontâneo e o meio ambiente é descoberto sem que haja uma perda do sentido de self. Ao reagir, a criança sente que o mundo externo a invade tendo, assim, a necessidade de reagir a essa invasão, dificultando o desenvolvimento saudável do ego. $\mathrm{O}$ conto nasce da cantiga de ninar, na narrativa criada pela relação afetiva entre mãe e bebê (Safra, 2011).

Para Safra (2011), as histórias favorecem o aparecimento do espaço potencial, pois elas são uma forma de comunicação, que possibilita à criança falar de si mesma, ser compreendida, de usar sua própria imaginação, sem ser invadida. É com as histórias que a criança entra em contato com suas angústias e com aquilo que ocasionou uma parada no seu desenvolvimento. Aqui, a criança, tem a oportunidade de transformar suas experiências em elementos toleráveis e passíveis de serem colocados sob domínio de seu gesto e espontaneidade. Além disso, é no espaço potencial que a criança encontra um lugar de refúgio nos momentos mais difíceis, em vez de escolher a via da sintomatologia e da doença (Gutfreind, 2010). Ainda, segundo Gonçalves e Braga (2015), as histórias são consideradas um instrumento capaz de evitar um desregramento emocional na medida em que podem absorver o retorno do material reprimido e ameaçador, desencadeando um processo de elaboração e impedindo a paralisia do pensamento. 


\section{A IMPORTÂNCIA DO NARRAR E DO BRINCAR: UMA VISÃO PSICANALÍTICA}

Gutfreind (2010) e Costa e outros (2013) também são autores que destacam a importância do conto como um mediador entre a criança e seus conflitos. Assim, ler ou ouvir contos podem possibilitar que a criança continue pensando nela mesma, no momento em que entra em contato com sentimentos e conflitos difíceis de serem suportados e que, sem esse filtro da narrativa, poderia paralisar sua capacidade associativa ou ainda lhe causar sintomas.

A narrativa insere as situações de vida no registro da temporalidade humana, de inicio, meio e fim, de maneira que cada conflito ou impasse acontece e em seguida tende a uma resolução ou fim. Na narrativa o vir a ser humano está devidamente contemplado e é nela que a criança encontra um sentido para as suas experiências.

Enfim, podemos afirmar que com o advento da psicanálise, o interesse pelos mitos, lendas e contos de fadas se deu de maneira intensa, uma vez que muitos estudiosos(Winnicott D. W., 1975; Ferro, 1995; Bettelheim, 2002; Radino, 2003; Safra, 2006; Corso \& Corso, 2006; Gutfreind, 2010; Safra, 2011) descobriram a riqueza simbólica e a utilidade das histórias infantis, que trazem importantes contribuições para o entendimento da vida psíquica da criança.

Por fim, os contos não só divertem as crianças, mas como proporciona a ela um maior conhecimento de si mesma, além do favorecimento do desenvolvimento de sua personalidade (Port e outros, 2014). Os contos facilitam a organização de sentimentos complexos e ambivalentes, viabilizando a crença da criança numa solução mais feliz para seus problemas.

\section{Ressonâncias clínicas do brincar e do narrar}

Observa-se, na clínica, que a brincadeira pode ser o meio e a forma de expressão da criança e de suas fantasias inconscientes, servindo para o psicoterapeuta interagir e ajudar a criança a compreender seus conflitos, ansiedades, desejos, fantasias e frustrações expressos no brincar e no narrar. No setting terapêutico, com a oferta de um ambiente acolhedor, é possibilitada a entrada no espaço potencial, havendo, assim, o brincar mútuo entre terapeuta e paciente, o que permite a formação de um vínculo promotor de saúde (Souza \& Assis, 2014). O essencial é a adaptação do setting às necessidades do paciente. Nas consultas, prevalece a arte de não-interpretar. Os comentários interpretativos são reservados para um momento especial e adequado, quando a criança estiver preparada para isso (Ferro, 1995; Lins, 2006).

No tocante aos contos, estes ajudaram Safra (2011) ao longo de seus 
anos de formação, a lidar com as suas experiências do cotidiano. Eram eles os seus interlocutores mais privilegiados, tanto é que os utilizou em sua prática clínica como método de intervenção com pacientes de diferentes idades. Com esse procedimento, o autor ajudou um número grande de crianças que hoje já são pais, os quais utilizam as histórias para intervir no cotidiano de seus próprios filhos. Esse procedimento de contar histórias está sendo usado cada vez mais por psicólogos e instituições como um meio breve de auxílio psicológico às crianças. Tal procedimento veicula o narrar como canal de intervenção, pois as histórias com suas metáforas permitem ao paciente que dê o primeiro passo na apreensão daquilo que estiver ao seu alcance e de acordo com seu tempo interno(Pereira \& Lemos, 2013).

Em nossa pesquisa, encontramos um rico acervo de publicações que discutem como os contos são utilizados como mediadores e veículos de intervenção na psicoterapia de crianças (Ferro, 1995; Gutfreind, 2010; Safra, 2011; Costa et al., 2013; Zatti \& Kern, 2014; Port e outros, 2014; Gonçalves \& Braga, 2015; Silva, Machado, Lacerda, \& Menegotto, 2015), autores que destacam a função dos contos, esta que vai além de mera distração, pois oferecem vários benefícios: elaboração dos conflitos internos e externos; auxílio à capacidade de suportar processos de separação e luto; o desenvolvimento da capacidade simbólica, do pensar, do fantasiar e do criar; a facilitação de comunicação com o outro; a expressão da criatividade; recursos estes necessários para o enfrentamento dos traumas e dificuldades que surgem ao longo do processo de crescimento e desenvolvimento da criança.

Para Safra (2005) é possível a utilização de mitos e objetos culturais na cura de pacientes. Trata-se de fornecer ao doente uma linguagem na qual possam ser expressos estados psíquicos não formulados, e que, de outro modo, seriam inarticuláveis. O terapeuta dialoga com seu paciente não pela palavra, mas por meio de operações concretas, verdadeiros ritos que atravessam a tela da consciência sem encontrar obstáculos, para levar sua mensagem ao inconsciente.

Levando em consideração os benefícios que as histórias e o brincar proporcionam, elas podem ser usadas como um instrumento de intervenção eficaz na psicoterapia e no psicodiagnóstico. Para Gutfreind (2010) e Safra (2011), com o auxílio da história, evita-se a necessidade de se fazer uma psicoterapia longa, sendo por esta razão, uma técnica muito útil, principalmente, no trabalho institucional, sendo a oficina terapêutica de contos um dispositivo 


\section{A IMPORTÂNCIA DO NARRAR E DO BRINCAR: UMA VISÃO PSICANALÍTICA}

clínico fundamental no atendimento de crianças.

\section{Considerações Finais}

Winnicott quando foi questionado sobre o porquê das crianças brincarem, respondeu que elas brincam por prazer, para exprimir agressividade, para controlar a angústia, para enriquecer suas experiências, para desenvolver contatos sociais, comunicar-se com pessoas escolhidas de seu meio ambiente, e utilizam a brincadeira como meio de integração da personalidade, tal como ocorre nas expressões artísticas e na religião.

$\mathrm{Na}$ contramão da temporalidade veloz, encontram-se o brincar e o narrar, como sinalizadores fundamentais da posição da criança no mundo. Assim é importante respeitar a especificidade da infância e faz-se necessário destacara importância destas atividades para a construção subjetiva, tanto das crianças quanto dos adultos, uma vez que somos todos seres lúdicos, criativos e dotados de uma biografia que nos tornam singulares em um mundo tão insensível ao tempo do ouvir histórias e do brincar.

Ao permitirmos à criança o brincar e o narrar, ela sentir-se-á segura e gradualmente capaz de lidar com os problemas do mundo externo e com seus conflitos internos, criando sentidos para a vida e confiança em si mesma. Ao lidar com os contos e com as brincadeiras livres e espontâneas que cria, ela mostra-se ativa, sendo agente e sujeito da ação que irá mediar sua relação, compreensão e apropriação de si e do mundo que a cerca. Ao contrário, considera-se que quando não são ofertados espaço e tempo para a criança brincar, entrar em contato com histórias e fantasiar, ela pode viver dificuldades de separação entre mundo interno e externo, dificultando sua integração como pessoa, ao empobrecer a vida real e de possibilidades de sentidos para ela.

\section{Referências}

Bettelheim, B. (2002). A psicanálise dos contos de fadas (16 ${ }^{\mathrm{a}}$ ed.). Paz e Terra.

Corso, D. L., \& Corso, M. (2006). Fadas no divã: psicanálise nas histórias infantis. Porto Alegre: Artmed. 
Costa, A. M., Cadore, C., Lewis, M. d., \& Perrone, C. M. (jan./jun. de 2013). Oficina terapêutica de contos infantis no CAPSi: Relato de uma experiência. Barbarói, 235249.

Ferro, A. (1995). A técnica na psicanálise infantil: a criança e o analista da relação ao campo emocional. Rio de Janeiro: Imago.

Gonçalves, M. d., \& Braga, A. A. (2015). Era uma vez... Os contos de fadas como recurso terapêutico com criancas hospitalizadas. Revista Psicologia, Diversidade e Saúde, 4, 5-20.

Granato, T. M., Corbett, E., \& Aiello-Vaisberg, T. M. (jan./mar. de 2011). Narrativa interativa e psicanálise. Psicologia em estudo, 16, 157-163.

Gutfreind, C. (2010). O terapeuta e o lobo: a utilização do conto na psicoterapia da criança. Rio de Janeiro: Artes e Ofícios.

Honoré, C. (2005). Devagar. Rio de Janeiro: Record.

Lemos, A. C., \& Silva, N. C. (Jan/Jul de 2012). A função terapêutica da arte de contar histórias. Intersemiose, I(1), 7-23.

Lins, M. I. (2006). Consultas terapêuticas (2 $2^{\mathrm{a}}$ ed.). São Paulo: Casa do psicológo.

Meira, A. M. (Jul./Dez. de 2012). A educação, o brincar e a infância contemporânea. Revista de Educação PUC, 17(2), 173-179.

Morabito, C. R., Sei, M. B., \& Arruda, S. L. (2012). Em defesa do brincar e do conto de fadas no desenvolvimento da criança. Ommia Saúde, 9, 67-82.

Oliveira, A. J. (2009). Uma questão de tempo. In: S. Pripas, Cronos Ensandeciso: sobre a agitação no mundo contemporâneo (p. 167). São Carlos: EdUSCar.

Pereira, V. O., \& Lemos, M. F. (Jul/Dez de 2013). A função terapêutica dos contos de fadas: sentimentos e conflitos humanos. Perspectivas em Psicologia, 17(2), 102-114.

Port, F. L., Henkin, R. S., Feijó, L. P., \& Brum, E. H. (Nov. de 2014). Contando recontando... Subjetivando: A importância terapêutica da psicanálise no grupo de contos. Anais da VIII Mostra Científica do Cesuca, 305-310.

Pripas, S. (2009). Cronos ensandecido: sobre a agitação do mundo moderno. São Carlos: EduFSCar.

Pripas, S. (2009). O ser sem tempo. In: S. Pripas, Cronos ensandecido: sobre a agitação no mundo contemporâneo (p. 167). São Carlos: EdUFSCar.

Radino, G. (2003). Contos de fadas e realidade psíquica: a importância da fantasia no desenvolvimento. São Paulo: Casa do Psicólogo.

Safra, G. (2005). A face estética do Self: teoria e Clínica. São Paulo: Unimarco. 


\section{A IMPORTÂNCIA DO NARRAR E DO BRINCAR: UMA VISÃO PSICANALÍTICA}

Safra, G. (2006). Desvelando a memória do humano: o brincar, o narrar, o corpo, o sagrado, o silêncio. São Paulo: Sobornost.

Safra, G. (2011). Curando com histórias (2ª ed.). São Paulo: Sobornost.

Silva, D. R., Machado, I., Lacerda, L. D., \& Menegotto, L. M. (2015). Alice e a escolha de uma caminho possível entre a fantasia e a realidade: a utilização dos contos na clínica infantil. Revista Saúde e Desenvolvimento Humano, 39-49.

Souza, J. O., \& Assis, M. d. (Jan/Jun de 2014). O brincar e o narrar: oferta de espaços potenciais em um mundo acelerado. Perspectivas em Psicologia, 18(1), 57-74.

Winnicott, D. W. (1975). O brincar e a realidade. Rio de Janeiro: Imago.

Winnicott, D. W. (1983). O ambiente e os processos de maturação. Porto Alegre: Artmed.

Zatti, C., \& Kern, C. D. (Set/Dez de 2014). A importância dos contos de fadas como instrumento de trabalho para a psicoterapia infantil. Revista da Sociedade de Psicologia do Rio Grande do Sul, 14(2), 06-17.

\section{Notas de rodapé}

Para que possa se constituir como um indivíduo, o ser humano conta com um potencial inato em direção ao amadurecimento, que necessita de um ambiente facilitador para se realizar. Este potencial herdado é o que Winnicott (1983) vai chamar de self central ou verdadeiro. Já diante da falha ambiental, o falso self se constitui como uma tentativa de substituição da função materna que falhou, na busca de proteger o verdadeiro self e darlhe condições para se desenvolver. Trata-se de uma forma primitiva de autossuficiência na ausência do cuidado. Podemos, então, entender o falso self como uma defesa que oculta e protege o verdadeiro self.

\section{Os Autores:}

Fausto Pereira da Silva é graduando em Psicologia pela Universidade Federal de Goiás, Regional Jataí, e.mail: faustojatai@hotmail.com

Maria de Fátima Pessoa de Assis possui graduação em Psicologia pela Universidade Federal de Minas Gerais, Mestrado em Educação pela Universidade Federal de Minas Gerais e Doutorado em Educação escolar pela Universidade Estadual Paulista, UNESP/Araraquara. Atualmente é professora Adjunta, da Universidade Federal de Goiás. E.mail: mafapessoa@gmail.com

Recebido em: 06/03/2017.

Aprovado em: 16/06/2017. 